\title{
The Semantic Web Architecture and its Impact on E-learning Systems Development
}

\author{
http://dx.doi.org/10.3991/ijet.v10i5.4754 \\ Samir A. El-Seoud ${ }^{1}$, Hosam F. El-Sofany ${ }^{2}$ and Omar H. Karam ${ }^{1}$ \\ ${ }^{1}$ The British University in Egypt-BUE, Cairo, Egypt \\ ${ }^{2}$ Cairo Higher Institute, Cairo, Egypt
}

\begin{abstract}
The Semantic Web is the next giant step of the current web technology. The use and application of the Semantic Web in E-learning has been explored with regard to two areas: 1) software that supports instructors to perform their tasks in flexible online educational settings, and 2) software that interprets the structure of distributed, self organized, and self-directed web-based learning. These two application areas and related tasks require a semantic representation of educational entities and pedagogical material, specifically the structure and the techniques of the teachinglearning process. In most E-learning systems users are able to manage and reuse learning contents according to their needs without any access problems. The main objectives of this study are: how can e-learning take advantage of Semantic Web technology, and how to integrate the Semantic Web technologies with e-learning systems, taking into consideration the standards and reusable learning objects (LO), and to show the advantages of improving the description of content, context and structure of the learning material. The main goal of this article it to introduce an updated Elearning model based on the latest Semantic Web architectures.
\end{abstract}

Index Terms-Learning Objects, E-learning, Ontology, Semantic Web, Web Based Learning.

\section{INTRODUCTION}

The significance of web-based learning is growing in all kinds of learning scenarios, and E-learning is generally seen as the chance to innovative learning. There are a lot of promises E-learning holds, for example that learning can take place anywhere, at the moment when it is needed. It can be individualized concerning time, place, duration, and learning style. Learning can be taken out of classrooms and formal education institutions, and integrated into working environments and into private lives. However, a truly effective E-learning solution must meet the growing demands for E-learning by students, employees, researchers and lifelong learners. Efficient management to the information available on the Web can lead to an Elearning environment that provides learners with interaction with the most relevant material.

The current WWW is a powerful tool for research and education, but its utility is hampered by the inability of the users to navigate easily the vague sources for the information they require. The Semantic Web is a vision to solve this problem. It is proposed that a new WWW architecture will support not only Web content, but also associated formal semantics. The Semantic Web appears as a promising technology for implementing E-learning. It constitutes an environment in which human and machine agents will communicate on a semantic basis [1]. The Semantic Web is about two things. It is about common formats for interchange of data, where on the original Web we only had interchange of documents. Also, it is about the language for recording how data relates to real world objects. This allows a person, or a machine, to start off in one database, and then move through an unending set of databases which are connected not by wires but by being about the same thing.

The paper is organized as follows: in section two we introduce the latest version of the semantic web architecture while in section three we present E-learning system requirements. In section four we present some issues about learning objects and E-learning standers. Also in this section we show the benefits of learning objects to learners and instructors. In section five we introduce the impact and benefits of Semantic Web in E-learning environment. In section six we introduce our updated version of conceptual E-learning model based on the Semantic Web architecture. The paper is finally concluded in section seven.

\section{Semantic Web ARChitecture}

The main model for our research in the Semantic Web is the layered architecture. The layered architecture consists of a number of layers organized hierarchically as in Fig. 1. It can take many shapes like the pyramid shape, the circular shape and the tower shape as in the Semantic Web. Each layer provides a service to its upper layer and serves as a client to the layer below. This kind of architecture depends on the sequence of incremental steps, which means the increasing level of abstraction: if the function of one layer changes, this means that two other layers may be affected. The most famous example for the layered architecture is ISO (International Standards Organization), and OSI (Open Systems Interconnected) [2]. The four versions of semantic web architecture that created by Tim Berners-Lee, are explained in many research articles. Here we present and explain only the latest one, as shown in Figure 1. 


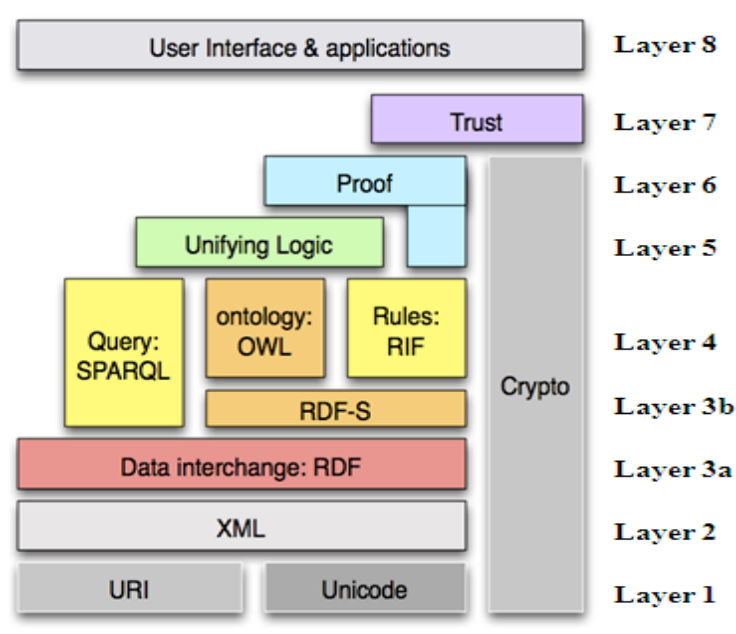

Figure 1. Latest Semantic Web Layered Architecture

\section{URI and Unicode layer}

This layer provides a simple and extensible way for identifying resources. A resource can be anything that has an identity such as a web site, a document, an image and a person. Unicode is considered as the universal standard encoding system for computer character representation. Most encoding systems represent only few languages while Unicode represents all languages.

\section{XML layer}

This layer describes what is in the document, not what the documents looks like, while XML Schema provides grammars for legal XML documents.

\section{Data interchange and RDF layer}

This layer uses URIs to identify web resources and uses a graph model for the purpose of describing the relationship between different resources. RDF Schema is a simple modeling language introducing classes of resources, properties and relations between them [3, 4].

\section{Ontology (OWL), query (SPAQL), RDF-S, and RIF layer}

Ontology is defined as the backbone for the Semantic Web architecture providing machine processable semantics and a sharable domain which can facilitate communication between people and different applications. The main objective of ontology is to provide semantics which produces a web of meaning. Ontologies will help machines to process the meaning and facilitate sharing of information [4]. RIF (Rule Interchange Format) specifies the XML format for rules at an intermediate expressive power compatible with RDF and OWL according to what is written by the RIF Working Group [11].

\section{Unifying Logic layer}

This layer provides the foundation for combining the above two layers technologies into a whole, with a unifying language to engage queries and rules over knowledge represented in RDF and associated ontologies and schemata. Various works in this area have looked at combining rules with querying, combining ontological interpretations with querying, and combining rules and ontologies.

\section{Proof layer}

This layer is used for checking the validity of specific statements.

\section{Trust layer}

This layer depends on the source of information as well as the policies available on the information source which can deny unwanted applications or users access to these sources. It is supposed to provide a mechanism for trust and confidence between information sources and parities.

\section{User Interface and Applications layer}

This layer deploys as a baseline that all user interfaces and applications should satisfy.

\section{Vertical layers: Crypto}

These layers are Encryption and Digital Signature. The layer starts from layer 1 up to layer 6. Digital signature: is a step towards a web of trust. By using an XML digital signature, any digital information can be signed. There are specific elements in XML syntax used for this process such as SignedInfo, Reference and DigestValue. XML Signatures can be applied to the content of resources and by this way every resource can be identified $[5,6]$.

\section{E-LEARNING SYSTEM REQUIREMENTS}

"E-learning" is just-in-time education integrated with high velocity value chains. It is the delivery of individualized, comprehensive, dynamic learning content in real time, aiding the development of communities of knowledge, linking learners and practitioners with experts [7].

The traditional learning process could be characterized by centralized authority (content is selected by the educator), strong push delivery (instructors push knowledge o students), lack of personalization (content must satisfy the needs of many students) and the static learning process (unchanged content). A detailed view of standard learning is given in Table 2. Such an organization results in a learning process that is expensive, slow and too unfocused (problem-independent) - while the dynamically changing business environment puts completely opposite challenges to the learning process requiring a fast, just-in-time (low in price) and relevant (problem-dependent) learning. This can be solved with the distributed, student-oriented, personalized and dynamic learning process - E-learning.

\section{A. Identifying user profiles, needs and tasks}

Once the context is defined, the user profiles that will interact with the system must be identified, and so must their needs and the tasks that they should be able to perform. Use cases are a standard technique for gathering requirements in many modern software development methodologies. A use case is one of the ways of using the system. The sum of all the available ways of using the system constitutes the functional requirements (what things the system will do and how, independently of the technology it will be used in the development and the way the user-system interaction will be performed). In [8] Constantine proposes some use cases description guidelines.

\section{B. Defining learning methodology}

It defines the way the learning will be performed and how it will match the different learning paradigms and learner orientations. As a result, the main elements of the learning process must be identified as well as the main features of each profile environment.

\section{Identifying the system entities}

The entities are all the items the user will take, handle, produce or use in his interaction with the system (i.e., 


\section{The SEMANTiC Web ARChiteCtURE AND ITS IMPACt ON E-LEARning SyStems DEVELOPMENT}

an inscription, an exam, a chapter, a mail, etc.). Each entity is defined and described by a set of attributes and states.

Apart from the entities identification it will be useful to elaborate a glossary with all the outstanding terms that appear in the requirements capture phase (i.e. validation date, setup date, etc.).

TABLE I.

DIFFERENCES BETWEEN TRAINING AND ELEARNING [7]

\begin{tabular}{|c|c|c|}
\hline Dimension & Traditional Learning & e-Learning \\
\hline Delivery & $\begin{array}{l}\text { Push - Instructor deter- } \\
\text { mine agenda }\end{array}$ & $\begin{array}{l}\text { Pull - Student determine } \\
\text { agenda }\end{array}$ \\
\hline Responsiveness & $\begin{array}{l}\text { Anticipatory - Assumes } \\
\text { to know the problem }\end{array}$ & $\begin{array}{l}\text { Reactionary - Responds } \\
\text { to problem at hand }\end{array}$ \\
\hline Access & $\begin{array}{l}\text { Linear - Has defined } \\
\text { progression of } \\
\text { knowledge }\end{array}$ & $\begin{array}{l}\text { Non-Linear - Allows } \\
\text { direct access to } \\
\text { knowledge in whatever } \\
\text { sequence makes sense to } \\
\text { the situation at hand }\end{array}$ \\
\hline Symmetry & $\begin{array}{l}\text { Asymmetric - Training } \\
\text { occurs as a separate } \\
\text { activity }\end{array}$ & $\begin{array}{l}\text { Symmetric - Learning } \\
\text { occurs as an integrated } \\
\text { activity }\end{array}$ \\
\hline Modality & $\begin{array}{l}\text { Discrete - Training } \\
\text { takes place in dedicated } \\
\text { chunks with defined } \\
\text { starts and stops }\end{array}$ & $\begin{array}{l}\text { Continuous - Learning } \\
\text { runs in the parallel loops } \\
\text { and never stops }\end{array}$ \\
\hline Authority & $\begin{array}{l}\text { Centralized - Content is } \\
\text { selected from a library } \\
\text { of materials developed } \\
\text { by the educator }\end{array}$ & $\begin{array}{l}\text { Distributed - Content } \\
\text { comes from the interac- } \\
\text { tion of the participants } \\
\text { and the educator }\end{array}$ \\
\hline Personalization & $\begin{array}{l}\text { Mass produced - Con- } \\
\text { tent must satisfy the } \\
\text { needs of many }\end{array}$ & $\begin{array}{l}\text { Personalizes - Content is } \\
\text { determined by the indi- } \\
\text { vidual user's needs and } \\
\text { aims to satisfy the needs } \\
\text { of every user }\end{array}$ \\
\hline Adaptively & $\begin{array}{l}\text { Static }- \text { Content and } \\
\text { organization/taxonomy } \\
\text { remains in their original } \\
\text { authored form without } \\
\text { regard to environmental } \\
\text { changes }\end{array}$ & $\begin{array}{l}\text { Dynamic - Content } \\
\text { changes constantly } \\
\text { through user input, expe- } \\
\text { rience, new practices, } \\
\text { business rules and heuris- } \\
\text { tics }\end{array}$ \\
\hline Delivery & $\begin{array}{l}\text { Push - Instructor deter- } \\
\text { mine agenda }\end{array}$ & $\begin{array}{l}\text { Pull - Student determine } \\
\text { agenda }\end{array}$ \\
\hline
\end{tabular}

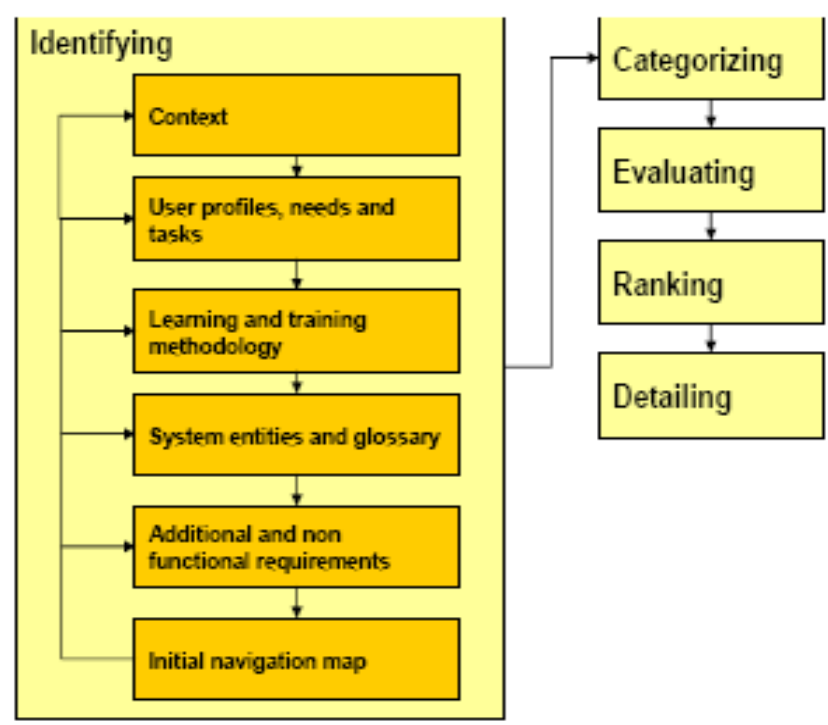

Figure 2. Learning systems requirement identification process

\section{Identifying additional and non functional requirements}

These requirements specify properties of the system such as accessibility, availability, reliability, and so on. They can affect some or all the functional requirements.

\section{E. Defining initial navigation map}

The navigation map is a view of the E-learning system showing how users will navigate in it. It can be represented in a hierarchical 'tree' diagram. Each level of the diagram shows the number of clicks that it takes to reach a screen page. Keeping the most important areas of the system only one click away from the first screen page will facilitate user tasks. Creating a system navigation map at the early stages of the project provides a valuable communication vehicle between stakeholders and the development team.

\section{LEARNING OBJECTS AND E-LEARNING STANDARDS}

There are several issues that need to be considered to decide when and how to integrate standards into e- learning content. Issues relevant to:

1. The E-learning project

2. The finished E-learning product

3. The workflow process

4. Reuse of components

5. Standards identification and application

\section{A. Learning Objects (LO)}

The concept of Learning Objects is grounded in the object-oriented paradigm of computer science [9]. The principle of Learning Objects is the creation of instructional components that can be reused numerous times in different learning contexts. A Learning Object is a unit of instructionally sound content centered on a learning objective or outcome intended to teach a focused concept. It is a fundamental building block composed of all the instructionally necessary components to comprise a selfcontained instructional unit. These multimedia learning materials as described by Hiddink (2001), EDUCAUSE (2005), and Gallenson et al. (2002) include, but are not limited to, simulations, electronic calculations, animations, tutorials, text entries, bibliographies, audio and video clips, quizzes, photographs, illustrations, diagrams, grafts, maps, charts, and assessments combined for the purpose of presenting interchangeable examples, arguments, cases, and practical exercises, which can be instructor guided or based on learner self-interest and self determined need [10].

This represented a new way of looking at curriculum in which content is broken up into discrete pieces or Learning Objects. Teachers and learners then go about the process of creating linkages between chunks in order to construct understanding.

These Learning Objects can be delivered over the Internet and can be accessed by a number of individuals simultaneously, with minimal effort, reducing the need for instructors to develop their own instructional components. They allow for increased speed and efficiency of instructional development and decrease faculty preparation time [9]. 


\section{B. Benefits of learning objects}

According to [12], the fundamental idea behind Learning

Objects is that instructional designers can build small instructional components that can be reused a number of times in different learning contexts. Additionally, Learning Objects are generally understood to be digital entities deliverable over the Internet, meaning that any number of people can access and use them simultaneously.

\section{Benefits to learners}

- Learning Objects allow for the creation of highly effective learning experiences for students [10] and enhancing the student learning environment [13];

- The choice of which Learning Objects to assemble into a collection can be a decision made in advance by an instructional designer or at the moment by a student [14];

- Learning Objects allow experiences in problemsolving and exploration and collaboration with fellow learners [14];

- Learning Objects allow universal access to online instructional materials;

- Learning Objects provide solutions for individualizing learning [10].

\section{Benefits for instructors}

- Learning Objects are highly interoperable and reusable modular building blocks or E-learning content based on widely shared specifications [15];

- Learning Objects promote better collaboration among developers [10];

- Learning Objects provide resources for instruction where there might not otherwise be [10];

- Learning Objects can be combined in nearly infinite ways to construct collections that might be called lessons, modules, courses or even curricula.

- Learning Objects allow for increased productivity among trainers and educators [10];

- Learning Objects provide value in terms of saving time and money in course development;

- Learning Objects allow for increases in the reusability of content;

- Learning Objects allow for sharing knowledge within and across disciplines ;

- Learning Objects engage faculty in a dynamic community of practice [13].

\section{Semantic Web And E-LEARNING}

E-learning systems and E-learning research areas can benefit from semantic web technologies. By a set of suitable agents which seem to be powerful enough, the Semantic Web technology is able to satisfy the E-learning requirements: fast, just-in-time and relevant learning. The possible enhancements and uses of the Semantic Web technology for E-learning are [7]:

Pull: Knowledge items (learning materials) are distributed on the web, but they are linked to commonly agreed ontologies. This enables construction of a user-specific course by semantic querying for topics of interest.

Interactivity: Software agents on the Semantic Web may use commonly agreed service language, which enables co-ordination between agents and proactive deliv- ery of learning materials in the context of actual problems. The vision is that each user has his own personalized agent that communicates with other agents.

Non-linearity: A User can describe a situation at hand (goal of learning, previous knowledge) and perform semantic querying for the suitable learning material. The user profile is also accounted for. Access to knowledge can be expanded by semantically defined navigation.

Symmetry: The Semantic Web (semantic intranet) offers the potential to become an integration platform for all business processes in an organization, including learning activities.

Continuity: Active delivery of information (based on personalized agents) creates a dynamic learning environment.

Distribution: The Semantic Web will be as decentralized as possible. This enables effective co-operative content management.

Personalization: A user (using a personalized agent) searches for learning material customized for her/his needs. The ontology is the link between the user needs and the characteristics of the learning material.

Dynamism: The Semantic Web enables the use of provided knowledge in various forms by semantic annotation of content. The Distributed nature of the Semantic Web enables continuous improvement of learning materials.

\section{A. Ontologies for E-learning}

In a typical E-learning environment authors or trainers produce their learning material in such a way so as to match the E-learning platform's architecture. This leads to situations where authors may use different terminologies, in which case the combining of learning materials becomes difficult. This problem affects the information and knowledge retrieval problem due to the fact that both instructors and learners have different knowledge backgrounds. Therefore, a mechanism for creating a shared-understanding and terminologies is required. Ontologies are a powerful mechanism for achieving this task [16].

Ontology provides a critical role for E-learning systems to formally describe a shared meaning of a vocabulary and a set of symbols through a set of possible mapping between symbols and their meanings. In E-learning systems, the shared-understanding problem occurs on many ontological levels in which the description of documents can be mapped in several aspects.

The most important issues to be considered when a learner searches for learning materials are [17]:

- Content of the learning material

- Context of the learning material (pedagogical issues)

- Structure of the learning material, to make sure that the learning material does not appear in isolation.

There are therefore three ontological levels to take in consideration: content, context, and structure [16].

Content ontology describes the basic concepts of the domain in which learning takes place (e.g., history or computer science). It includes also the relations between these concepts, and some basic properties. For example, the study of Classical Athens is part of the history of Ancient Greece, which in turn is part of Ancient History. The ontology should include the relation "is part of" and 


\section{THE SEMANTIC Web ARCHITECTURE AND ITS IMPACT ON E-LEARNING SySTEMS DEVELOPMENT}

the fact that it is a transitive property of an element. In this way, an automated learning support agent can infer that knowledge on Classical Athens can be found under Ancient History. The content ontology can also use relations to capture synonyms like 'creator' and 'writer' and abbreviations such as 'World Wide Web' and 'WWW'.

Contextual (pedagogical) issues can be addressed in a pedagogy ontology. Learning material can be presented in the various learning contexts, such as lecture, tutorial, example, figure, walk-through, exercise, solution, and so on. This helps in context-relevant searching for learning material as per user needs. For example, if one is searching for detailed explanation of a topic, it would be appreciated to have material which gives more examples.

Structure ontology is used to define the logical structure of the learning materials. E-learning is often a self-paced environment, so training needs to be broken down into small bits of information, which can be tailored to meet individual needs and skill gaps. But these chunks of knowledge should be well connected to create the whole course. Hence greater attention should be given to design the structure of E-learning materials. Typical knowledge of this kind includes hierarchical and navigational relations like previous, next, hasPart, isPartOf, requires, and isBasedOn. Relationships between these relations can also be defined; for example, hasPart and isPartOf are inverse relations. It is natural to develop E-learning systems on the Web; thus a Web ontology language should be used.

\section{B. How to Build-up Ontologies}

The main part of ontology based E-learning systems is the users; specifically learners and instructors. The first issue to be considered when developing ontologies is the capture and documentation of the most basic functional requirements from readers' viewpoint. The steps involved in building-up ontologies are [18]:

- Identification of the aim and the scope of the ontology

- Reuse of existing vocabularies

- Enumerating the most important terms in the ontology

- Defining the classes and their hierarchy

- Defining the properties of the classes

- Defining the features of the properties

- Creating instances

\section{CONCEPTUAl E-Learning Model Based On The SEMANTIC WEB}

In to develop semantic E-learning model that provides high-level service for users looking for appropriate online courses, one must consider technical concepts and issues such as a knowledge base, and ontology-based knowledge which are the core of the architecture. They play the role of a repository where ontologies metadata inference rules, educational resources, course materials and user profiles are stored. The metadata may be placed within the document itself or in some external metadata repository (e.g. an RDF repository). In the proposed model the metadata, rules and annotations are stored externally in the ontology and knowledge base. The advantages the introduced model is:
- Easy to retrieve meta-description stored in a database and it takes less space to store it.

- It is possible to have different descriptions of the learning material according to the different contexts .

Semantic search engines, is another concept that needs to be considered, for it provides an API with methods for querying the knowledge base. Next is the Inference Engine which answers queries and is responsible for inferring new facts by an intelligent combination of facts already in the knowledge base.

The user Interface part provides an integrated interface through which readers as well as user/administrators of academic institutions can access, upload or modify the data with particular authority. The proposed model can integrated and considered when developing semantic Elearning architecture to form the conceptual E-learning system based on the semantic web as shown in Fig. 3. [19].

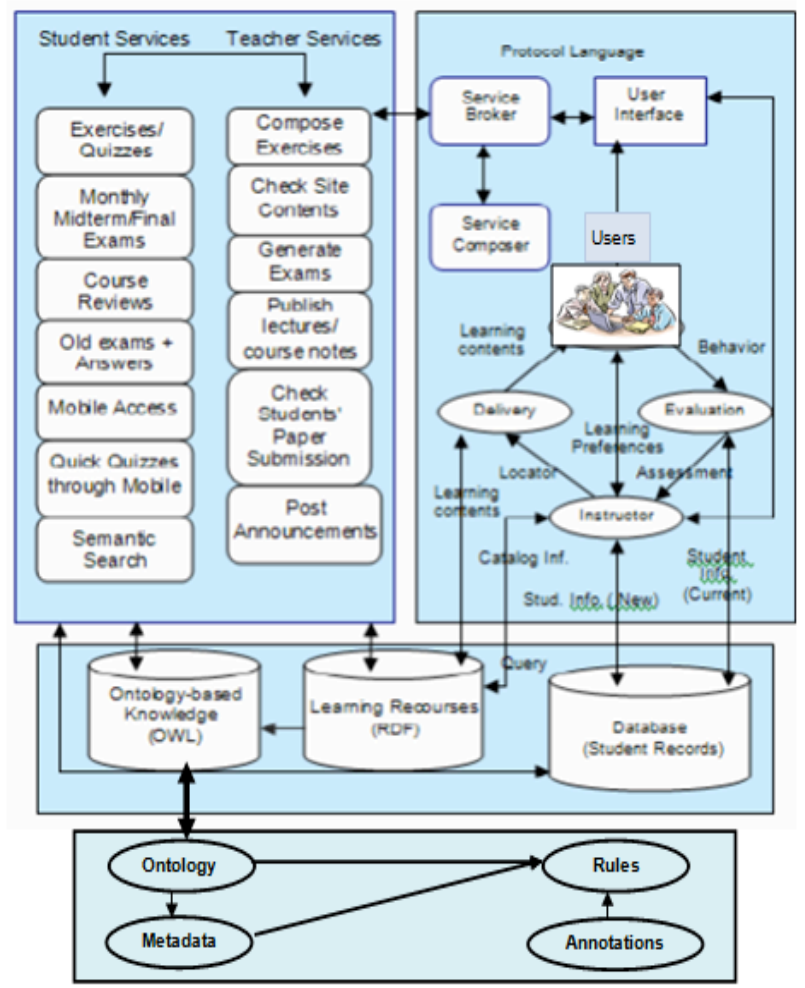

Figure 3. Conceptual E-learning Model Based on the Semantic Web

\section{CONCLUSION}

The Semantic Web is the emerging technology aiming at web-based information and services that would be understandable and reusable by both humans and machines. One of its primary components is ontology, generally defined as a representation of a shared conceptualization of a particular domain. It is expected that semantic web technologies will influence the next generation of Elearning systems and applications. This paper discussed how the semantic web can help develop an E-learning platform which provides a common interface for learners, instructors, authors and administrators of academic institutions for accessing learning materials.

The main objectives of this paper are: how can elearning take advantage of Semantic web technology, and how to integrate the semantic web technologies with e- 


\section{The SEMANTIC Web ARChITECTURE AND ITS IMPACT ON E-LEARNING SySTEMS DEVELOPMENT}

learning systems, taking into consideration the standards and reusable learning objects. Also, the study shows the advantages of improving the descriptions of content, context and structure of the learning material and the benefits of providing access to the learning material. The authors introduced an updated E-learning model based on the latest Semantic Web architectures.

\section{REFERENCES}

[1] Berners-Lee T. (2000). What the semantic web can represent, http://www.w3.org/DesignIssues/RDFnot.html

[2] Garlan, D. and M. Shaw, 1993. An Introduction to Software Architecture. In: Advances in Software Engineering and Knowledge Engineering, Ambriola, V. and Tortora, G., (Eds.). World Scientific Publishing Company, New Jersey. http://www.cs.cmu.edu/afs/cs/project/vit/ftp/pdf/intro_softarch.pdf http://dx.doi.org/10.1142/97898127980390001

[3] Buraga, S. and G. Ciobanu., 2002. A RDF- based model for expressing spatio-temporal relation between web sites. In The 3rd International Conference on Information Systems Engineering. IEEE Computer Society. pp: 355. IEEE Computer Society Washington, DC, USA. http://ieeexplore.ieee.org/xpl/freeabs_all.jsp? arnumber $=1181671 \&$ abstract Access $=$ no\&userType $=$ inst

[4] Matthews, B., (2005). Semantic Web Technologies. JISC Technology and Standards Watch,Joint Information Systems Committee, http://www.jisc.ac.uk/index.cfm?name=techwatch ic reports 2005 published\#reports

[5] Mark Bartel, John Boyer, Barb Fox and Brain La Macchia, et al. XML Signature Syntax and Processing (Second Edition). W3C Recommendation 10 June 2008. http://www.w3.org/TR/xmldsigcore/

[6] Russell Cloran and Barry Irwin, 2005. XML Digital Signature and RDF. http://icsa.cs.up.ac.za/issa/2005/Proceedings/Poster/026 Article.pdf

[7] Drucker P. (2000). Need to Know: Integrating e-Learning with High Velocity Value Chains, A Delphi Group White Paper. http://www.delphigroup.com/whitepapers/pdf/20001213-e-learnin g-wp.pdf

[8] Constantine, L. L. and Lockwood, L. A. D. (2000) Structure and Style in Use Cases for User Interface Design. [Online] Available: http://citeseerx.ist.psu.edu/viewdoc/download?doi=10.1.1.94.8255 \&rep=rep $1 \&$ type $=$ pdf

[9] Freeman, V. S. (2004). Learning objects in microbiology: A new resource. Clinical Laboratory Science, 17(2), 80. http://www.highbeam.com/doc/1P3-638023501.html

[10] Parrish, P. E. (2004). The trouble with learning objects. Educational Technology, Research and Development,52(1), 49-68. http://link.springer.com/article/10.1007\%2FBF02504772\#page1http://dx.doi.org/10.1007/BF02504772

[11] Boley, H. and M. Kifer, 30 July 2008. RIF Basic Logic Dialect. W3C Working Draft. http://www.w3.org/TR//2008/WD-rif-bld20080730/.

[12] Wiley, D. A. (2000). Connecting learning objects to instructional design theory: A definition, a metaphor, and a taxonomy. In D. A. Wiley (Ed.), The instructional use of learning objects: Online version: http://reusability.org/read/chapters/wiley.doc

[13] EDUCAUSE (2005). Learning objects. http://www.educause.edu/ contnet.asp?page_id $=2601 \&$ bhcp

[14] De Salas K. and Ellis L. (2006) The Development and Implementation of Learning Objects in a Higher Education Setting, Interdisciplinary Journal of Knowledge and Learning Objects Volume 2, 2006 http://www.ijklo.org/Volume2/v2p001-022deSalas.pdf

[15] Clyde, L. A. (2004). Digital learning objects. Teacher Librarian, $31(4), 55-58$.

[16] Dutta, B., Semantic Web Based E-learning. DRTC Conference on ICT for Digital Learning Environment 11th - 13th January, 2006, DRTC, Bangalore

[17] Antoniou, Grigoris and Harmelen, Frank van. A semantic web primer. 2004: MIT Press, London: http://www.dcc.fc.up.pt/ zpp/aulas/1112/pde/geral/bibliografia/MIT.Press.A.Semantic.Web .Primer.eBook-TLFeBOOK.pdf.
[18] Santos, Juan M., Anido, Luis and Llamas, Martin. Design of a Semantic Web-based Brokerage Architecture for the E-learning Domain. A Proposal for a Suitable Ontology. http://fie.engrng.pitt.edu/fie2005/papers/1461.pdf

[19] Hosam F. El-Sofany, and Samir A. El-Seoud, "Towards Development of Web-based Assessment System Based on Semantic Web Technolog ${ }^{\text {"n }}$. International Journal of Interactive Mobile Technologies (iJIM), Vol. 5, Issue 1, Pages 22-30, doi:10.3991/ijim.v5i1.1439, January 2011. http://www.iclconference.org/dl/proceedings/2010/contributions/Contribution1 28.pdf and http://dx.doi.org/10.3991/ijim.v5i1.1439

\section{AUTHORS}

Professor Samir Abou El-Seoud received his BSc degree in Physics, Electronics and Mathematics from Cairo University in 1967, his Higher Diploma in Computing from the Technical University of Darmstadt (TUD) - Germany in 1975 and his Doctor of Science from the same University (TUD) in 1979. Professor El-Seoud held different academic positions at TUD Germany. He has been a Full-Professor since 1987. Outside Germany Professor El-Seoud spent several years as a Full-Professor of Computer Science at SQU - Oman, at Qatar University, at PSUT and acted as a Head of Computer Science for many years. With industrial institutions, Professor ElSeoud worked as Scientific Advisor and Consultant for the GTZ in Germany and was responsible for establishing a postgraduate program leading to M.Sc. degree in Computations at Colombo University, Sri-Lanka (2001 2003). He also worked as an Application Consultant at Automatic Data Processing Inc., Division Network Services in Frankfurt/Germany (1979 - 1980). Professor El-Seoud joined PSUT in 2004. Currently. Professor ElSeoud is with the Faculty of Informatics and Computer Science of the British University in Egypt (BUE) and his email is samir.seoud@bue.edu.eg.

Dr. Hosam F. El-Sofany received his Ph.D. and his M. Sc. degree in Computer Science from Ain Shams University in 2008 and 1995 respectively. He is currently an Assistant Professor of CS in Cairo Higher Institute, and Director of Educity Center for Learning and Scientific Research. He has a strong technical background including designing and implementing Web-based systems. He has published many research papers related to E-learning technology in various international journals and conferences. His research is focused on E-Learning, MLearning, XML Databases, Databases Systems, and Semantic Web Applications. Dr. El-Sofany's e-mail address is hosam_elsofany@hotmail.com.

Professor Omar H. Karam obtained his B.Sc. (1980) in Engineering (Communications and Electro-physics) from Alexandria University and his M.Sc. (1987) and Ph.D. (1993) degrees in Computer Engineering from North Carolina State University. Dr. Karam is currently with the Faculty of Informatics and Computer Science of the British University in Egypt (BUE). He is on secondment from Ain Shams University, Egypt. Prior to the BUE, Dr. Karam was the Director of the Egyptian Universities Network (EUN). He has extensive professional experience in ICT management. Dr. Karam's e-mail address is omar.karam@bue.edu.eg.

Manuscript received 26 May 2015. This work was supported in part by The British University in Egypt - BUE. Published as resubmitted by the authors 30 October 2015. 